\title{
A Study of Multi-Scale Relationship Between Investor Sentiment and Stock Index Fluctuation Based on the Analysis of BEMD Spillover Index
}

\author{
Weiguo CHEN \\ College of Economics and Management, Beijing University of Technology, Beijing 100124, China; \\ China Post Group Corporation Limited Training Center, Shijiazhuang 050021, China \\ E-mail: chungweiguo@126.com \\ Shufen ZHOU \\ China Post Group Corporation Limited Training Center, Shijiazhuang 050021, China \\ E-mail: zhoushufen@126.com \\ Yin ZHANG \\ College of Economics and Management, Beijing University of Technology, Beijing 100124, China \\ E-mail: Zhangyin4-28@163.com \\ Yi SUN* \\ School of Finance, Anhui University of Finance and Economics, Bengbu 233000, China \\ E-mail: pony7766@163.com
}

\begin{abstract}
According to behavioral finance theory, investor sentiment generally exists in investors' trading activities and influences financial market. In order to investigate the interaction between investor sentiment and stock market as well as financial industry, this study decomposed investor sentiment, stock price index and SWS index of financial industry into IMF components at different scales by using BEMD algorithm. Moreover, the fluctuation characteristics of time series at different time scales were extracted, and the IMF components were reconstructed into short-term high-frequency components, medium-term important event low-frequency components and long-term trend components. The short-term interaction between investor sentiment and Shanghai Composite Index, Shenzhen Component Index and financial industries represented by SWS index was investigated based on the spillover index. The time difference correlation coefficient was employed to determine the medium-term and long-term correlation among variables. Results demonstrate that investor sentiment has a strong correlation with Shanghai Composite Index, Shenzhen Component Index and different financial industries represented by SWS index at the original scale, and the change of investor sentiment is mainly influenced by external market information. The interaction between most markets at the short-term scale is weaker than that at the original scale. Investor sentiment is more significantly correlated with SWS

Received October 27, 2020, accepted July 21, 2021

Supported by Special Project for Soft Science Research of Hebei Provincial Science and Technology Plan (202150302410011)

*Corresponding author
\end{abstract}


Bond, SWS Diversified Finance and Shanghai Composite Index at the long-term scale than that at the medium-term scale.

Keywords investor sentiment; spillover index; BEMD algorithm

\section{Introduction}

Traditional financial theory holds that asset price is determined by the intrinsic value. The arbitrage behavior of rational investors will continuously correct the wrong pricing in the market, and investor sentiment cannot systematically influence the market price. As financial market has continuously developed and market transaction has become increasingly complex, traditional financial theory cannot explain some financial anomalies in reality, such as Allais paradox, calendar effect, equity premium puzzle, option smile, closed-end mutual fund puzzle and the effect of small-cap stocks. In view of these financial anomalies, financial economists overthrew the basic hypotheses of traditional financial theory and explained the financial anomalies from the perspectives of psychology, behavioral science and sociology, thus forming behavioral finance from the perspective of investor behavior. Behavioral finance theory argues that investors are not completely rational or always risk-averse, but have limited rationality. Noise traders are influenced by market environment and their sentiment, and they influence market transactions in turn, which will eventually lead to mispricing. There is an interaction between investor sentiment and financial market. Based on the noise trader model, De Long, et al. ${ }^{[1]}$ found that investor sentiment is a systematic risk influencing the equilibrium price of financial assets, which triggers a further discussion on the relationship between investor sentiment and capital market. However, the existing studies focus on the influence of investor sentiment on capital market, while the influence of capital market on investor sentiment is seldom considered. In the real market, investor sentiment and capital market show complex relationship. Investor sentiment is the systematic deviation of investors' expectations ${ }^{[2]}$. In economic activities, investor sentiment has an impact on investment decisions by influencing their subjective judgment on future earnings, thus influencing the capital market. Investor sentiment also varies with market environment. In a bull market, the increasing demands lead to the continuous rise of asset prices and the increase of return on asset. The change of market environment will attract more investors, which further boosts investor sentiment. For the financial markets that boom and bust frequently, the dynamic change of investor sentiment has become an important factor affecting the stability of the market. For the rapidly developing Chinese capital market, the degree of irrationality is far higher than that of mature capital market, and the volatility of the market is more obvious. To explore the role of investor sentiment in the process of Chinese capital market volatility and the role of different industries in Chinese capital market volatility, clarifying these issues is not only of theoretical value for economic research, but also has important practical significance for the governance of China's capital market.

\section{Literature review}

De Long, et al. ${ }^{[1]}$ proposed a Noise Trader Model (DSSW), which is a generation overlapping model containing noise traders. In the model, irrational traders with random false beliefs can influence asset prices and earn higher expected returns. In the limited arbitrage environment, 
if investor sentiment influences each other, the unpredictability of noise traders' beliefs causes price risks. Consequently, arbitrageurs cannot eliminate the mispricing caused by irrational behavior, and asset price will deviate significantly from the intrinsic value. Investor sentiment is a systematic risk which can influence the equilibrium price of financial assets. DSSW model can be used to analyze the closed-end fund discount puzzle based on its own theory, triggering extensive research on the proposition that noise trader risk influences asset equilibrium price. Scholars have done a lot of research using econometric model to analyze the effect of investment. Some scholars used regression model to investigate the impact of investor sentiment on market returns. Sayim, et al. ${ }^{[3]}$ used vector auto-regression model to examine the influence of rational and irrational sentiment of institutional investors and individual investors in the United States on the returns and volatility of stock market in Istanbul. Kadilli ${ }^{[4]}$ examined the role of investor sentiment in predicting the annual stock returns of financial companies within the regression analysis framework. Chen, et al. ${ }^{[5]}$ used the panel threshold model to test the influence of sentiment of local investors and global investors on the expected industry stock returns in 11 Asian countries from 1996 to 2010. Some scholars used regression model to investigate asymmetric features of investor sentiment. Chung, et al. ${ }^{[6]}$ studied the asymmetry of investors' emotional prediction ability in the economic expansion period and the economic recession period based on the multivariate Markov-switching model. $\mathrm{Ni}$, et al. ${ }^{[7]}$ employed the panel quantile model to test the asymmetric relationship between investor sentiment and stock monthly returns in China's A-share market. Hudson and Green ${ }^{[8]}$ used the first principal component method to determine the sentiment of individual investors and institutional investors in Britain, and then used regression model to investigate the influence of investor sentiment on stock returns during the instability and stability periods in financial market. Some scholars used regression model to analyse the relationship between investor sentiment and market returns. Zhang, et al. ${ }^{[9]}$ revised the theoretical model of noise trading proposed by De Long, and carried out factor analysis to construct comprehensive investor sentiment index based on market turnover rate, closed-end fund discount and growth rate of account opening. Meanwhile, factor analysis was carried out to construct comprehensive investor sentiment index. In this study, OLS and GARCH-M Return analysis method were employed to analyze the relationship between investor sentiment and stock returns in China's stock market. Chi and Zhuang ${ }^{[10]}$ applied panel data model to study the relationship between investor sentiment and stock returns in China. Dong, et al. ${ }^{[11]}$ established a single-factor model and a multi-factor model based on quantile regression to study the correlation between high sentiment, low sentiment and market returns. The majority of the existing studies have studied the relationship between investor sentiment and capital market from multiple perspectives. However, on the one hand, the studies discuss the influence of investor sentiment on capital market in the time domain based on traditional econometric models, but ignore the frequency domain information of financial data and cannot completely describe the relationship between investor sentiment and stock market. In addition, the traditional financial statistical model usually requires stable time series. Similar to signal, most stock market time series data contains noise, and has the characteristics of nonlinearity, non-stationary, sharp peak and fat tail. The existing studies focus on the time domain dynamic correlation between investor sentiment and capital market in the time dimension, but the frequency domain dynamic corre- 
lation between investor sentiment and capital market is seldom involved. Li and Feng ${ }^{[12]}$ used EEMD method to decompose investor sentiment and stock index price series, and investigated the fluctuation correlation between investor sentiment and stock index price series at different time scales based on traditional econometric analysis. However, the dynamic characteristics of spillover effect were not considered. As argued by Perters ${ }^{[13]}$, the financial market is composed of traders with different investment time levels, such as short-term investment, medium-term investment and long-term investment. Different types of traders with different time scales have different investment ideas, and they influence the market from different time scales. Therefore, it is necessary to study the relationship between investor sentiment and stock market returns at different time scales from a multi-scale perspective. Financial time series has the characteristics of engineering signal. Many scholars have applied time-frequency analysis method to analyze financial time series, extract information at different scales, and reveal the inherent characteristics of data. Chinese scholars represented by Xie, et al. ${ }^{[14]}$ made up for the defect that empirical mode algorithm is based on IMF following the definition of narrowband signal and analyzed a set of power data by using local narrowband decomposition algorithm to guide power distribution. Xie, et al. ${ }^{[15]}$ used the improved empirical mode decomposition algorithm to analyze the analog signal and the actual signal, and proved that the essential mode function obtained by bandwidth criterion not only approximates the real component but also reflects the intrinsic information of the analyzed signal. Moreover, the power consumption data was decomposed into periodic term and trend term by bandwidth EMD. Based on the multi-scale characteristics of stock price fluctuation, Wang, et al. ${ }^{[16]}$ measured the portfolio risk with HSI Index and Shanghai Composite Index as data samples by using BEMD-Copula-GARCH model. Wu, et al. ${ }^{[17]}$ applied empirical mode decomposition (EMD) algorithm to decompose the multi-scale characteristics of China's live pig price. Also, structural change point analysis algorithm was employed to test the structural change points of each characteristic mode, and the four modes of live pig price in China were analyzed. Sun, et al. ${ }^{[18]}$ decomposed the national risk value of 12 OPECs into three time scales: Short term, medium term and long term, and studied the fluctuation characteristics, modal characteristics and global importance between each scale and the original national risk series. On the basis of Diebold and Yilmaz's ${ }^{[19,20]}$ generalized variance decomposition idea, this study constructed the spillover effect index of investor sentiment and stock market, analyzed the influence scale and direction of investor sentiment, and discussed the relationship between investor sentiment and capital market. Moreover, sliding window technology was employed to explore the dynamic characteristics of spillover effect. Based on BEMD (bandwidth empirical mode decomposition, BEMD) method, this study overcame the shortcomings of previous single time domain or frequency domain analysis by combining time domain analysis and frequency domain analysis, and clearly presented the signal characteristics in time-frequency domain, which can hardly be obtained in single time domain or frequency domain. Also, the dynamic characteristics of spillover effect were analyzed by using window rolling technology. BEMD method can be applied to decompose all kinds of signal, and has high signal-to-noise ratio in dealing with non-stationary and non-linear data. This study used BEMD method to decompose investor sentiment and market indexes into the sum of several IMF components and residual items. Zhang's method ${ }^{[21]}$ was employed to reconstruct IMF and 
residual items into short-term fluctuation item, medium-term major event impact item and trend item. Based on spillover index and time difference correlation coefficient between variables, the interaction between investor sentiment and various variables was explored. This study made contributions in two aspects: 1) By establishing investor sentiment index, BEMD method was used to effectively avoid the possible problems of scale mixing and over-decomposition of traditional EMD algorithm and decompose the financial time series data into time series of different scales, then the relationship between investor sentiment, stock market and financial industries represented by SWS Index was studied at the original scale, long-term, medium-term and short-term scales. On the basis of the analysis of the "time domain dynamic correlation", the "frequency domain dynamic correlation" is further analyzed, and the rolling time window technology is introduced to analyze the dynamic relationship. 2) There is interaction between investor sentiment and capital market. On the one hand, investor sentiment influences capital market. On the other hand, capital market also has an impact on investor sentiment. But the existing research ignores the impact of the capital market on the investor sentiment at different time scales. This study investigated the static and dynamic interaction between investor sentiment and each market at different scales by using spillover index.

\section{Construction of Investor Sentiment Index}

The sources of investor sentiment index are mainly divided into two categories: One is to directly investigate investor sentiment, including direct indexes like questionnaire. Such indexes include CCTV BSI and Shenzhen Securities Information Company ICI. Since 2001, the CCTV website has established CCTV BSI index by investigating the predication of afternoon market by securities companies and consulting institutions to reflect investors' views on the trend of stock market. Shenzhen Securities Information Co., Ltd. has compiled a systematic, precise and highly professional investor confidence index, which is only used for internal research and cannot be extensively and deeply studied. China's media or organizations have limited surveys of investor sentiment, and the continuity of surveys and the availability of data are poor. In addition, these surveys are generally conducted among institutional investors, and cannot cover the sentiment of individual investors. The other is indirect indexes measuring investor sentiment. Investor sentiment indexes are constructed based on the transaction data about investor sentiment in the market, and can be used to analyze future market conditions. Such indexes include not only the overall market performance indexes formed by summarizing the overall performance data of the stock market, but also the transactional sentiment indexes constructed from the perspective of the types of market trading behaviors. This study used BW sentiment index construction method (Wurgler and Baker ${ }^{[22]}$ ) and selected three proxy variables: Turnover rate of weighted market value of A shares in circulation (Turn RMC), price earning ratio of A share in Shanghai Stock Exchange (Pe) and Advance/Decline line of A share in Shanghai Stock Exchange. Moreover, the advance and decline influence of the three variables was comprehensively considered, and principal component analysis was carried out to construct investor sentiment index. 


\section{Study of Spillover Index Based on BEMD}

Since the traditional EMD algorithm has the problem of scale mixing, the extracted IMF may contain oscillation with a large frequency range, and sometimes may be over-decomposed. Therefore, by combining BEMD and spillover index analysis, this study used the bandwidth empirical mode decomposition (BEMD) proposed by Xie, et al. ${ }^{[15]}$ to extract the short-term scale information of time series data. Moreover, the short-term scale relationship between investor sentiment and variables was studied based on the spillover index. Base on the EMD algorithm, sifting process in BEMD can be summarized as follows.

Given a time-series $f(t), t=1,2, \cdots, N$, threshold value $T$, let $r(t)=f(t)$.

1) Find all local minima and maxima of $r(t)$.

2 ) Get the upper envelop $e_{\max }(t)$ by interpolating between maxima. Similarly get the lower envelop $e_{\min }(t)$ with minima.

3) Compute the mean envelop as an approximation to the local average, $m(t)=\left(e_{\max }(t)+\right.$ $\left.e_{\min }(t)\right) / 2$.

4) Extracted the proto-mode function $(\mathrm{PMF}): p_{i}(i)=r(t)-m(t)$, and let $r(t)=p_{i}(t)$.

5) Repeat Steps $1 \sim 4$ on PMF $p_{i}(i)$, stop criterion is presented by next three subsidiary process;

a) Use 3 -thresholds $\alpha_{1}, \theta_{1}, \theta_{2}$ criterion to get PMF that almost satisfies the two conditions of IMF.

b) Continue the sifting process until we find the minimum for $\sigma_{\mathrm{PMF}}^{2}$.

c) Take the final PMF as an IMF, then the IMF has small frequency bandwidth mild scale mixing problem. Then record the IMF $i m f_{k}(t)=p_{i}(t)$.

6) Let $r(t)=r(t)-i m f_{k}(t)$, if the extremum point number of $r(t)$ is larger than three, let $k=k+1, i=0$, and go to Step 1$)$; otherwise finish the sifting process. According to the BEMD algorithm, IMF with the weakest scale mixing can be obtained.

As the short-term scale information extracted by BEMD belongs to high-frequency information and meets the stability requirements of series, a VAR model can be established. This study applied the spillover index method based on forecast error variance decomposition proposed by Diebold and Yilmaz ${ }^{[19,20]}$ to measure the short-term scale relationship between investor sentiment and stock market indexes. The model can be summarized as follows: $p$-order vector auto-regression $\operatorname{VAR}(p)$ model considering $n$ variables with stationary covariance is as below:

$$
x_{t}=\sum_{i=1}^{p} \Phi x_{t-i}+\epsilon_{t} r
$$

where, the error term $\epsilon \sim(0, \Sigma)$ is an independent and identically distributed random variable. The moving average of $x_{t}$ is expressed as below:

$$
x_{t}=\sum_{i=0}^{\infty} A_{i} \epsilon_{t-i},
$$

where, the $N \times N$ coefficient matrix $A_{i}$ obeys recursive form $A_{i}=\Phi_{1} A_{i-1}+\Phi_{1} A_{i-2}+\cdots+$ $\Phi_{1} A_{i-p} . A_{0}$ is $N \times N$ identity matrix and $A_{i}=0$ when $i<0$. Through variance decomposition, 
the prediction error variance of each variable was decomposed into various system shocks, and the $H$-step error variance of $x_{i}$ caused by $x_{j}$ was evaluated.

The decomposition based on generalized VAR does not need to orthogonalize shock. The decomposition results are robust and not affected by variable ordering. The generalized VAR method allows related shock, which is explained by the historical distribution of errors, instead of orthogonalizing shock. Since the shock to each variable is not orthogonal, the sum of variances of prediction errors (the row sum of elements in variance decomposition table) is not necessarily equal to 1.

In order to measure the spillover effect among variables, the $H$-step error variance caused by the impact of $x_{i}$ is defined as self-spillover, while the $H$-step error variance caused by the impact of $x_{j}$ is interactive spillover. $H$-step prediction error variance is decomposed into $\theta_{i j}^{g}(H)$, $H=1,2, \cdots$,

$$
\theta_{i j}^{g}(H)=\frac{\sigma_{j j}^{-1} \sum_{h=0}^{H-1}\left(e_{i}^{\prime} A_{h} \sum e_{j}\right)^{2}}{\sum_{h=0}^{H-1}\left(e_{i}^{\prime} A_{h} \sum A_{h}^{\prime} e_{j}\right)},
$$

where $\Sigma$ is the variance matrix of error vector $\epsilon . \quad \sigma_{j j}$ is the standard deviation of the $j$-th equation error. $e_{i}$ is the selection vector. The $i$-th element is 1 , and other elements are 0 . As explained earlier, the sum of the elements in each row of the variance decomposition table is not equal to 1 , namely $\sum_{j=1}^{N} \theta_{i j}^{g}(H) \neq 1$. To use the available information in the variance decomposition matrix to calculate the overflow index, the row sum was employed to standardize the input of the variance decomposition matrix.

$$
\widetilde{\theta}_{i j}^{g}(H)=\frac{\theta_{i j}^{g}(H)}{\sum_{j=1}^{N} \theta_{i j}^{g}(H)} .
$$

In order to measure the contribution of fluctuation shocks of all variables to the total prediction error variance, the total spillover index is defined as below.

$$
S g(H)=\frac{\sum_{i, j=1, i \neq j}^{N} \widetilde{\theta}_{i j}^{g}(H)}{\sum_{i, j=1}^{N} \widetilde{\theta}_{i j}^{g}(H)} \times 100=\frac{\sum_{i, j=1, i \neq j}^{N} \widetilde{\theta}_{i j}^{g}(H)}{N} \times 100 .
$$

Directional spillover index $S_{i .}^{g}(H)$ measures the spillover intensity of all other variables to variable $i$, which is called the total directional acceptance index of $i$. The directional spillover index $S_{i .}^{g}(H)$ measures the total spillover intensity of variable $i$ to all other variables, which is called the total directional spillover index of $i$. The calculation formula is as follows:

$$
\begin{aligned}
& S_{i .}^{g}(H)=\frac{\sum_{j=1, j \neq i}^{N} \widetilde{\theta}_{i j}^{g}(H)}{\sum_{i, j=1}^{N} \widetilde{\theta}_{i j}^{g}(H)} \times 100=\frac{\sum_{j=1, j \neq i}^{N} \widetilde{\theta}_{i j}^{g}(H)}{N}, \\
& S_{. i}^{g}(H)=\frac{\sum_{j=1, j \neq i}^{N} \widetilde{\theta}_{j i}^{g}(H)}{\sum_{i, j=1}^{N} \widetilde{\theta}_{j i}^{g}(H)} \times 100=\frac{\sum_{j=1, j \neq i}^{N} \widetilde{\theta}_{j i}^{g}(H)}{N} .
\end{aligned}
$$

The net spillover index measures the net spillover effect of market $i$ to other markets $j$, which is the difference between the total fluctuation shocks from and to other markets. The calculation formula is as below:

$$
S_{i}^{g}(H)=S_{. i}^{g}(H)-S_{i .}^{g}(H)
$$


To sum up, this study first decomposed the original data into a series of empirical modal functions with different frequencies by BEMD. Second, the data was reorganized to extract the fluctuation information at different scales. As the short-term fluctuation information belongs to high-frequency data and meets the requirement of data stationarity, the VAR model can be established directly, and the total spillover index, the directional spillover index and the net spillover index can be obtained by decomposing the generalized prediction error variance.

\section{Empirical Analysis}

\subsection{Measurement of Investor Sentiment Index}

On the basis of the daily trading data from January 24, 2007 to December 27, 2018, this study selected three proxy variables: Turnover rate of weighted market value of A shares in circulation (Turn RMC), price earning ratio of A share in Shanghai Stock Exchange (Pe) and Advance/Decline line of A share in Shanghai Stock Exchange. Since different variables have advance or lag in the influence of investor sentiment, the advance and lag effects of the three variables in index synthesis were comprehensively considered, and the advance and lag variables of the three variables were selected to construct investor sentiment index by carrying out principal component analysis, as shown in Table 1.

Table 1 Principal component analysis

\begin{tabular}{|c|c|c|c|c|c|c|}
\hline \multicolumn{7}{|c|}{ Total Variance Explained } \\
\hline \multirow[b]{2}{*}{ Component } & \multicolumn{3}{|c|}{ Initial Eigenvalues } & \multicolumn{3}{|c|}{ Extraction Sums of Squared Loadings } \\
\hline & Total & $\%$ of Variance & Cumulative $\%$ & Total & $\%$ of Variance & Cumulative $\%$ \\
\hline 1 & 2.684 & 44.733 & 44.733 & 2.684 & 44.733 & 44.733 \\
\hline 2 & 1.479 & 24.647 & 69.38 & 1.479 & 24.647 & 69.38 \\
\hline 3 & 1.27 & 21.175 & 90.555 & 1.27 & 21.175 & 90.555 \\
\hline 4 & 0.516 & 8.605 & 99.16 & & & \\
\hline 5 & 0.048 & 0.795 & 99.956 & & & \\
\hline 6 & 0.003 & 0.044 & 100 & & & \\
\hline
\end{tabular}

Three principal components were extracted:

$$
\begin{aligned}
\text { index } 1= & 0.48 \operatorname{TurnRMC}+0.48 \mathrm{Pe}+0.2 \mathrm{ADL}+0.49 \operatorname{TurnRMC}(-1) \\
& +0.48 \mathrm{Pe}(-1)+0.17 \mathrm{ADL}(-1) . \\
\text { index } 2= & 0.19 \operatorname{TurnRMC}-0.43 \mathrm{Pe}+0.53 \mathrm{ADL}+0.23 \operatorname{TurnRMC}(-1) \\
& -0.41 \mathrm{Pe}(-1)+0.52 \mathrm{ADL}(-1) . \\
\text { index } 3= & -0.49 \operatorname{TurnRMC}+0.3 \mathrm{Pe}+0.4 \mathrm{ADL}-0.45 \operatorname{TurnRMC}(-1) \\
& +0.31 \mathrm{Pe}(-1)+0.46 \mathrm{ADL}(-1) .
\end{aligned}
$$

Finally, variance percentage weight was conducted to construct composite sentiment index:

$$
S E N T=0.45 \text { index } 1+0.25 \text { index } 2+0.21 \text { index } 3 .
$$




\subsection{Analysis of Multi-Scale Spillover Effect}

In order to study the influence of market volatility on investor sentiment, this study collected the daily trading data of Shanghai Composite Index, Shenzhen Component Index, SWS Bank Index, SWS Insurance Index, SWS Securities Index and SWS Diversified Financial Index from January 24, 2007 to December 27, 2018, and investigated the interaction between investor sentiment and Shanghai Composite Index, Shenzhen Component Index and financial industries represented by SWS index. When decomposing data using BEMD method, the number of decomposed integrations was set to 100 , and the standard deviation of white noise was 0.1 . The method proposed by Zhang ${ }^{[22]}$ was employed to reorganize IMF components and extract short-term fluctuation information, medium-term major event impact information and longterm trend information of the series. Moreover, the interaction between market fluctuation and investor sentiment at different scales was analyzed.

By comparing and analyzing the reorganized IMF, we can more intuitively analyze the periodic fluctuations of investor sentiment, stock price index and SWS index. Generally speaking, high-frequency data represent the short-term fluctuation of time series influenced by irregular information, which lasts for a short time and fluctuates seriously. Low-frequency data represent the time series influenced by major events like financial crisis, which makes time series change greatly and have strong periodicity. The trend term reflects the basic trend of time series.

\subsubsection{Analysis of Spillover Effect at Original Scale}

First of all, the interaction between investor sentiment and Shanghai Composite Index, Shenzhen Component Index and financial industries conducted with static full sample spillover effect analysis. Second, rolling window technology was employed to study the dynamic characteristics of spillover effect among variables.

1) Analysis of total spillover effect

By constructing the full sample spillover index of generalized predictive variance decomposition of the first 10 days in advance, a $7 \times 7$ matrix was obtained, as shown in Table 2 . The $i j$-th element in the table represents the contribution of variable $j$ to predictive error variance of variable $i$. Diagonal elements were employed to measure the spillover effects within elements, while non-diagonal elements were applied to measure the spillover effects between elements.

According to the data in the table, the total internal spillover index between investor sentiment and Shanghai Composite Index, Shenzhen Component Index, the financial industries represented by SWS Index is $65.52 \%$, showing a strong correlation. On the whole, the internal spillover of variables is generally higher than that between variables. Particularly, the investor sentiment is affected most significantly, and the spillover index is up to $99.5 \%$. Other variables have little influence on investor sentiment. Being self-strengthening, investor sentiment is high stimulated by good news, which spreads through different media and generates positive feedback effect on the stock market, thereby promoting the rise of stock price. The rising stock price further stimulates the rise of investor sentiment. However, the Shanghai Stock Exchange and the Shenzhen Stock Exchange are special, that is, the spillover effect of Shanghai Stock Exchange is slightly smaller than that of Shenzhen Stock Exchange. 
Table 2 The internal total spillover index between investor sentiment and Shanghai Composite Index, Shenzhen Component Index, financial industries represented by SWS Index at original scale

\begin{tabular}{|c|c|c|c|c|c|c|}
\hline Investor & Shanghai & Shenzhen & $\begin{array}{c}\text { SWS } \\
\text { Diversified }\end{array}$ & SWS & SWS & SWS \\
\hline sentiment & $\begin{array}{c}\text { Composite } \\
\text { Index }\end{array}$ & $\begin{array}{c}\text { Component } \\
\text { Index }\end{array}$ & $\begin{array}{l}\text { Finance } \\
(801191)\end{array}$ & $\begin{array}{c}\text { Bank } \\
(801192)\end{array}$ & $\begin{array}{c}\text { Bond } \\
(801193)\end{array}$ & $\begin{array}{c}\text { Insurance } \\
(801194)\end{array}$ \\
\hline
\end{tabular}

\begin{tabular}{|c|c|c|c|c|c|c|c|c|}
\hline $\begin{array}{l}\text { Investor } \\
\text { sentiment }\end{array}$ & 99.5 & 0.03 & 0.07 & 0.04 & 0.04 & 0.05 & 0.28 & 0.51 \\
\hline \multicolumn{9}{|l|}{ Shanghai } \\
\hline Composite & 7.6 & 13.51 & 17.27 & 8.1 & 20.85 & 10.13 & 22.54 & 86.49 \\
\hline \multicolumn{9}{|l|}{ Index } \\
\hline \multicolumn{9}{|l|}{ Shenzhen } \\
\hline $\begin{array}{l}\text { Component } \\
\text { Index }\end{array}$ & 7.04 & 14.25 & 25.3 & 10.59 & 14.85 & 10.17 & 17.8 & 74.7 \\
\hline $\begin{array}{l}\text { SWS Diversified } \\
\text { Finance (801191) }\end{array}$ & )$^{7.09}$ & 11.79 & 16.15 & 20.33 & 16.09 & 15.56 & 12.98 & 79.66 \\
\hline SWS Bank & & & & & & & & \\
\hline$(801192)$ & 24.6 & 7.55 & 7.11 & 3.37 & 23.29 & 6.58 & 27.49 & 76.7 \\
\hline SWS Bond & & & & & & & & \\
\hline (801193) & 13.45 & 10.31 & 12.46 & 12.11 & 18.47 & 18.33 & 14.87 & 81.67 \\
\hline $\begin{array}{l}\text { SWS Insurance } \\
(801194)\end{array}$ & 32.34 & 5.23 & 6.44 & 2.41 & 9.78 & 2.69 & 41.1 & 58.89 \\
\hline$S_{\text {to }}$ & 92.12 & 49.16 & 59.5 & 36.62 & 80.08 & 45.18 & 95.96 & 65.52 \\
\hline$S_{\text {net }}$ & 91.61 & -37.33 & -15.2 & -43.04 & 3.38 & -36.49 & 37.07 & \\
\hline
\end{tabular}

In view of the overall spillover effect, The insurance industry has the strongest spillover effect, reaching $95.96 \%$. The investor sentiment has the second strongest spillover effect, reaching $92.12 \%$, but the influence from other markets is only $0.51 \%$, indicating the information outside the market is the main factor leading to the change of investor sentiment. Investor sentiment is an important factor influencing the securities market. The insurance industry and banking industry represented by SWS Index have more influence on other markets compared with the factors outside the market. As for the spillover effect of investor sentiment on a single variable, investor sentiment has the strongest spillover effect on the insurance industry and the weakest spillover effect on the diversified Finance. Considering the spillover effects of various financial industries on Shanghai Stock Exchange and Shenzhen Stock Exchange, except for self-spillover, the spillover effects of the banking industry and the insurance industry are the strongest. The net spillover effects of the banking industry and the insurance industry are great, indicating that the business relevance of different financial institutions has been enhanced with the deepening of the mixed operation in the financial industry. The banking industry and the insurance industry have similarity in capital adequacy ratio, solvency and risk matching ability, and the 
cross-industry and cross-market contagion of financial risks continuously increases.

2) Analysis of dynamic spillover effect

Spillover effect generally varies over time. The correlation between different variables may be aggravated or weakened in uncertain conditions, and the static spillover index may ignore the influence of new information during the sample period. In order to effectively test the time-varying characteristics of spillover effect between investor sentiment and variables, this study introduced rolling time window technology to ensure smooth expression of index and avoid information distortion. The sample size of the sliding window was set 300, and the rolling step size was 10. As Figure 1 shows, The dynamic spillover index indicates that the spillover index between investor sentiment and various markets is in the range of $65 \% \sim 75 \%$ from 2007 to 2018, showing strong correlation. Also, the spillover index between investor sentiment and various markets has great volatility, which is obviously influenced by information. There are three major fluctuations, which occurred in October 2009-July 2010, February 2014-December 2014, May 2017-October 2018. The 2009 financial crisis has not completely disappeared, and there is still a long way to go for economic recovery. The sales restriction and ban lifting has brought heavier pressure in the securities market. However, as the Chinese government issued the 4-trillion economic stimulus plan in November 2008, and the GEM market landed on the capital market stage, the multi-level capital market was gradually improved, and investor sentiment has been enhanced. The securities market finally closed big red line, and the turnover of the Shanghai Stock Exchange and the Shenzhen Stock Exchange also reached a record high. With the tightening of real estate policy and monetary policy in 2010, higher demands were raised for IPO financing and refinancing in the capital market, and the capital pressure in the secondary market was doubled. The A-share market represented by Shanghai Composite Index fell far beyond the major global stock indexes, only better than that in Greece and Spain which suffered from European debt crisis. With the continuous decline of stock indexes, investors were depressed. In 2014, as China comprehensively deepened the reform of economic system and released the reform dividend, the capital market finally got rid of the bear market which lasted for nearly seven years and ushered in a new round of bull market. The investor sentiment kept rising, leading to the increase of the spillover index. Affected by three key factors, namely overseas factors represented by Sino-US trade friction, the continuous shrink of credit contraction represented by the continuous decline in the growth rate of social financing, and the continuous strengthening of financial supervision represented by the formulation of new regulations on asset management, the A-share market continued to slump in 2018, and the turnover of Shanghai stock market hit a new low in more than four years. By the end of 2018, the number of investors was 145 million, the market value decreased by 14.59 trillion yuan, and the per capita loss of A-share investors was 100,600 yuan. Investors were depressed and the spillover index kept falling. 


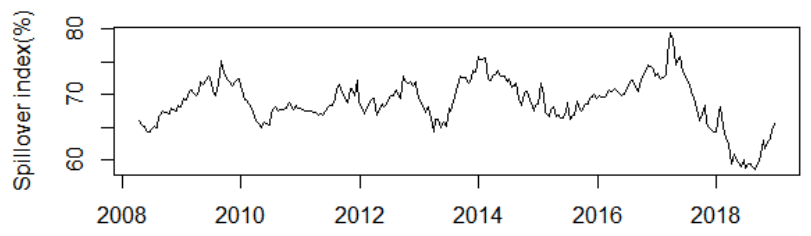

Figure 1 The dynamic spillover index between the investor sentiment and each market at original scale

3) Analysis of directional spillover effect

Figure 2 shows the investor sentiment and the directional spillover index and net spillover index of each market from 2007 to 2018, which reflects the trend of investor sentiment and information spillover between each market and all other markets. It can be seen from the figure that there is uncertainty and volatility between investor sentiment and the directional spillover index of each market, which is greatly influenced by various market information. Investors' sentiment and the total directional acceptance of each market have the opposite trend to the total directional spillovers, while the total directional spillovers and net spillovers tend to be consistent. From the overall directional acceptance of each index, due to the influence of the fuse mechanism and the new regulations of capital market reduction, the overall directional acceptance of investor sentiment and insurance market are in a higher position in 2016, and the spillover index is in a higher position, mainly the receiver of information, while the Shanghai Composite Index, diversified finance and bank's overall directional acceptance are in a relatively low position, while the spillover index is in a lower position. It is mainly the transmitter of information. From the total directional spillover of each index, the total directional spillover index of investor sentiment is in a high position in 2018. From this, it can be judged that in 2018, the worst-performing stock market was the Chinese A-share market, and besides the constant trade friction between China and the United States, the downward pressure on the domestic economy and the relatively low real economy, the low investor sentiment is also an important cause.
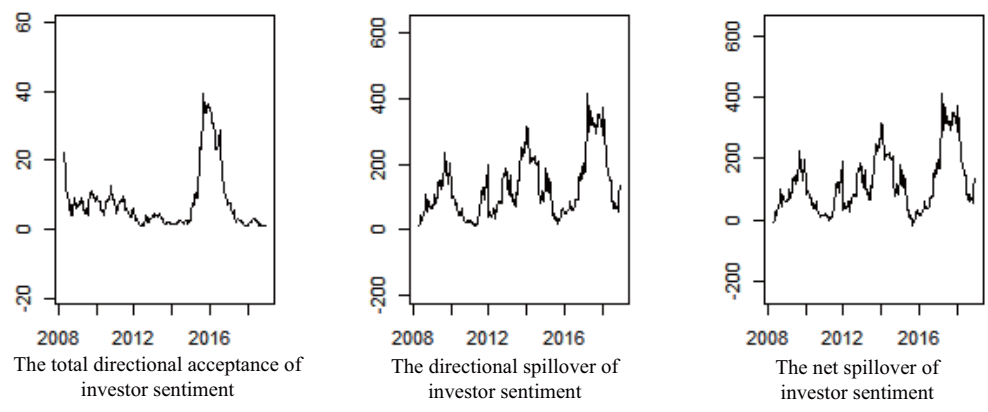

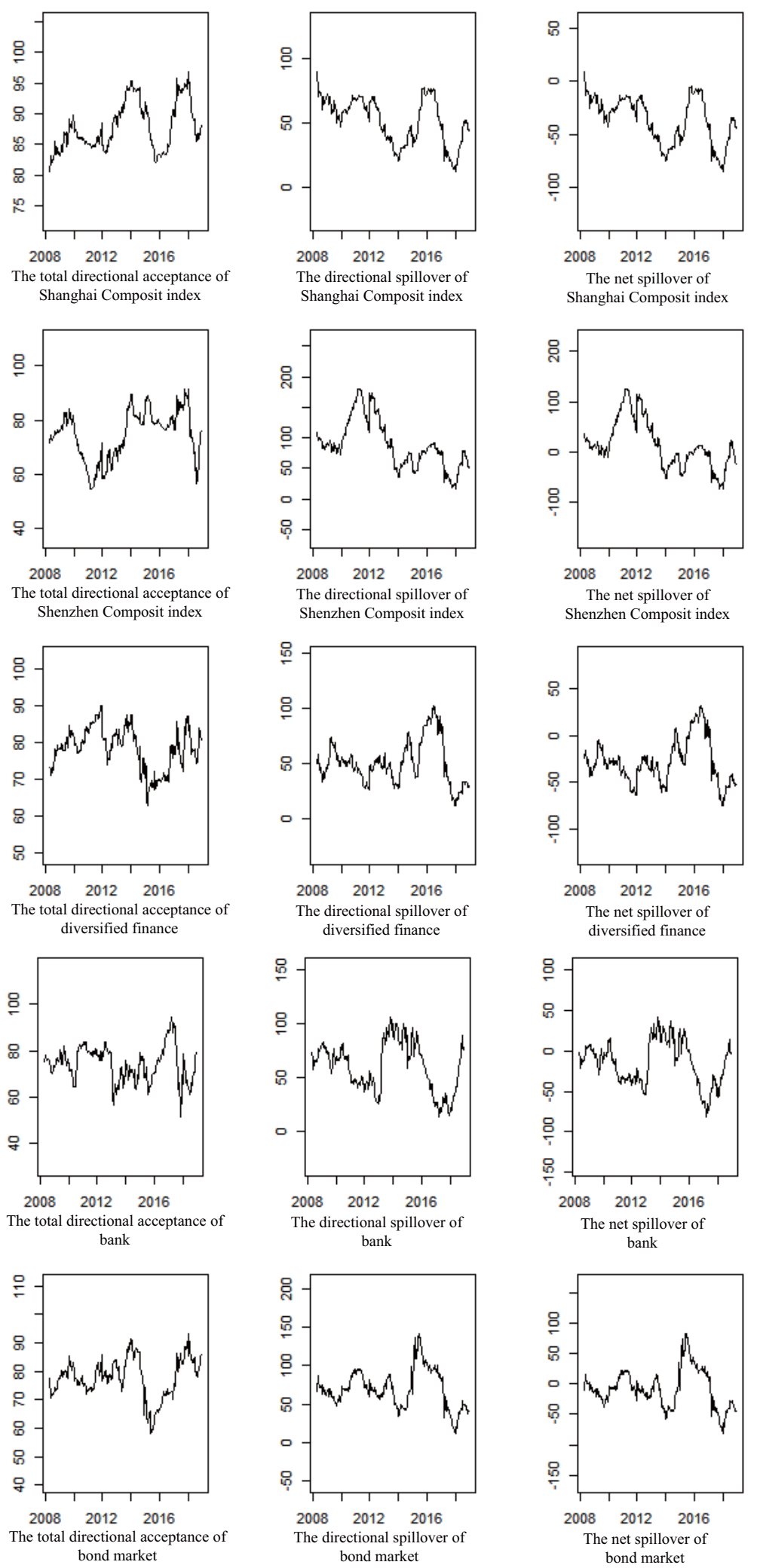

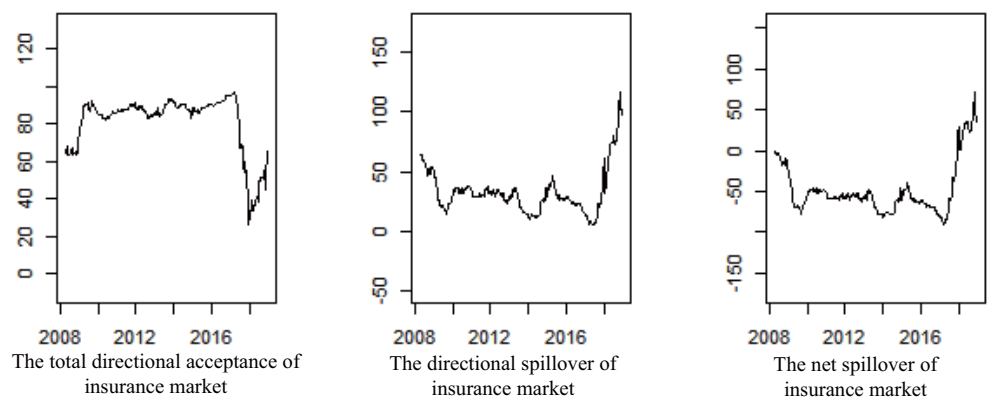

Figure 2 The directional spillover index and net spillover index between the investor sentiment and each market at original scale

4) Robustness test

To test the robustness of the total spillover effect, an optional $H$-step prediction error decomposition and an optional $W$-day sliding window are used. In this paper, 200-day and 300-day sliding windows, 10-step and 30-step prediction steps are selected for robustness test, and the test results are shown in Figure 3. No matter how the size of sliding window and prediction step are chosen, the dynamic overflow graph shows similar patterns, which shows that the analysis results are robust and consistent.

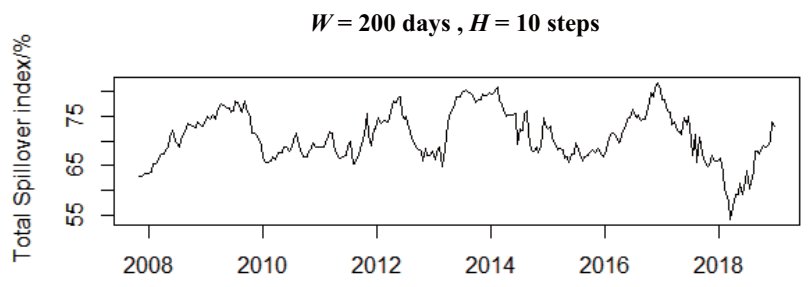

Figure 3 The dynamic spillover index of 200-day sliding windows and 10-step prediction steps at original scale

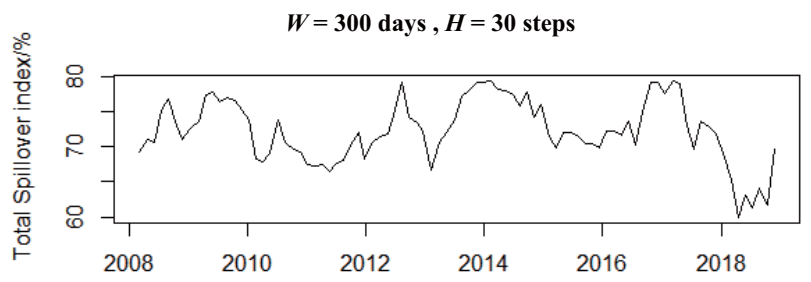

Figure 4 The dynamic spillover index of 300-day sliding windows and 30-step prediction steps at original scale

\subsubsection{Analysis of Short-Term Scale Spillover Effect}

1) Analysis of total spillover effect

From Table 3 of High Frequency Data Spillover, it can be seen that the internal total spillover index between investor sentiment and Shanghai Composite Index, Shenzhen Component Index, 
Table 3 The internal total spillover index between investor sentiment and Shanghai Composite Index,

Shenzhen Component Index, financial industries represented by SWS Index at the short-term scale

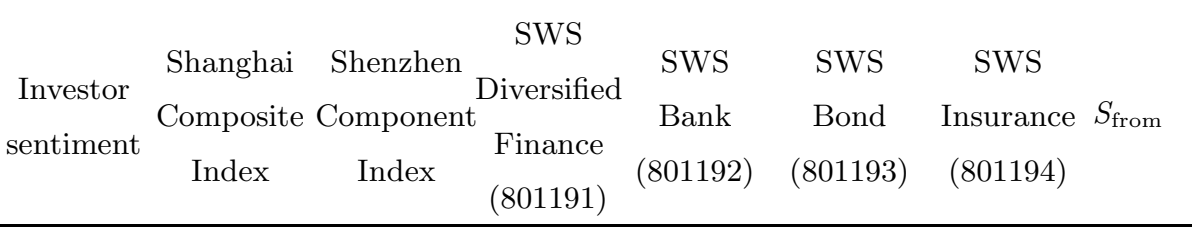

\begin{tabular}{|c|c|c|c|c|c|c|c|c|}
\hline $\begin{array}{l}\text { Investor } \\
\text { sentiment }\end{array}$ & 99.80 & 0.02 & 0.03 & 0.02 & 0.06 & 0.01 & 0.05 & 0.20 \\
\hline \multicolumn{9}{|l|}{ Shanghai } \\
\hline Composite & 39.14 & 10.06 & 11.34 & 4.20 & 21.03 & 4.48 & 9.75 & 89.94 \\
\hline \multicolumn{9}{|l|}{ Index } \\
\hline \multicolumn{9}{|l|}{ Shenzhen } \\
\hline Component & 57.78 & 5.50 & 14.76 & 3.72 & 8.09 & 3.32 & 6.82 & 85.24 \\
\hline \multicolumn{9}{|l|}{ Index } \\
\hline $\begin{array}{l}\text { SWS Diversified } \\
\text { Finance (801191) }\end{array}$ & 61.54 & 3.47 & 6.65 & 11.55 & 7.15 & 4.88 & 4.75 & 88.45 \\
\hline \multicolumn{9}{|l|}{ SWS Bank } \\
\hline$(801192)$ & 44.76 & 3.23 & 2.62 & 0.97 & 39.59 & 1.63 & 7.20 & 60.41 \\
\hline \multicolumn{9}{|l|}{ SWS Bond } \\
\hline (801193) & 52.71 & 4.24 & 7.73 & 5.35 & 12.05 & 12.60 & 5.32 & 87.40 \\
\hline $\begin{array}{l}\text { SWS Insurance } \\
(801194)\end{array}$ & 43.36 & 3.86 & 4.53 & 1.92 & 17.72 & 1.73 & 26.90 & 73.10 \\
\hline$S_{\text {to }}$ & 299.29 & 20.32 & 32.89 & 16.19 & 66.10 & 16.05 & 33.90 & 69.25 \\
\hline$S_{\text {net }}$ & 299.09 & -69.62 & -52.35 & -72.26 & 5.69 & -71.35 & -39.2 & \\
\hline
\end{tabular}

financial industries represented by SWS Index is up to $69.25 \%$, which is higher than the spillover index at the original scale. The correlation among variables is greater than that at the original scale. Investor sentiment has greater influence on each market at the short-term scale than that at the original scale, reaching $299.29 \%$. On the whole, the internal spillover is generally higher than the spillover between variables. Particularly, investor sentiment is most affected by its own impact, up to $99.8 \%$, while other variables have less influence on investor sentiment. However, compared with the original scale data, except that the internal spillover of investor sentiment and the banking industry increases, other indexes decrease in different degrees. Apart from investor sentiment and the bank industry, the total directional acceptance of each market at the short-term scale is larger than that at the original scale. Except for investor sentiment, the total directional spillover index of each market at the short-term scale is smaller than that at the original scale, indicating that investor sentiment is the main variable affecting other market, and except bank industry all markets are more susceptible to new market information. Moreover, the interaction between most markets is weaker than that at the original scale. The total directional acceptance index of the banking industry at the short-term scale is smaller 
than that at the original scale, and the total directional giving index is smaller than that at the original scale too. Therefore, banks are unlikely to be influenced by other market information in the short term, but are more likely to influence other markets. It shows that the role of banking market in risk spillover in the short term is less than that in the original scale.

2) Analysis of dynamic spillover effect

According to the dynamic spillover index, as Figure 5 shows, the spillover index between investor sentiment and each market was maintained at 60\% 70\% from 2007 to 2018. Compared with the original scale, the dynamic spillover curve at the short-term scale is flatter, and the spillover effect is smaller. The significant difference of the dynamic spillover graph at the original scale and the short-term scale appeared in 2015. In the short term, investor sentiment and various industries had greater feedback to relevant information in 2015, and the spillover index was larger. In China's stock market, the stock index increased substantially in the first half of 2015, while the stock market crashed and the stock price fell sharply on June 15 . The regulatory authorities took various measures to rescue the market. Moreover, the CSRC and the Ministry of Public Security cracked down on malicious short selling. In order to curb the herd effect that investors may sell into corrections, decrease the volatility of the capital market, enable investors to fully disseminate and feedback information, reduce information asymmetry and price uncertainty, and prevent sharp price fluctuations, Shanghai Stock Exchange, Shenzhen Stock Exchange and China Financial Futures Exchange officially issued relevant provisions of index circuit breaker and launched the circuit breaker mechanism at the end of 2015 .

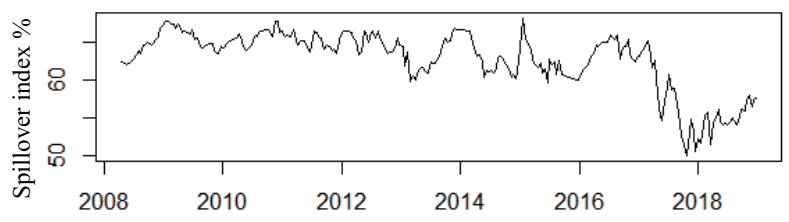

Figure 5 The dynamic spillover index between the investor sentiment and each market at the short-term scale

3) Analysis of directional spillover effect

Figure 6 shows the directional spillover index and net spillover index between the investor sentiment and each market at the short-term scale from 2007 to 2018, which reflect the shortterm trend of information spillover of investor sentiment as well as each market and all other markets. The total directional acceptance index at the short-term scale is smaller than that at the original scale. The difference between the total directional acceptance index of investor sentiment and the original scale appeared in 2008 and 2016. The 2008 financial crisis had a greater impact on investor sentiment at the short-term scale than that at the original scale, while fuse system had a smaller impact on investor sentiment than that at the original scale. Obviously, external events have greater impact on investor sentiment at the short-term scale. There were significant differences between Shanghai Composite Index and Shenzhen Composite Index in 2018. The total directional acceptance index of Shanghai Composite Index in 2018 was in the trough position of index at the short-term scale and in the peak position at the original scale. The total directional acceptance index of Shenzhen Composite Index was in the 
trough position at the original scale. In 2018, the Shanghai Composite Index was less affected by external events at the short-term scale, while the Shenzhen Composite Index was obviously influenced by external events at the original scale. The total directional spillover index of investor sentiment, Shanghai Composite Index, Shenzhen Component Index, bond market and insurance market is small at the short-term scale. The total directional spillover index of banks is small at the original scale. There is little difference in diversified finance between the shortterm scale and the original scale.
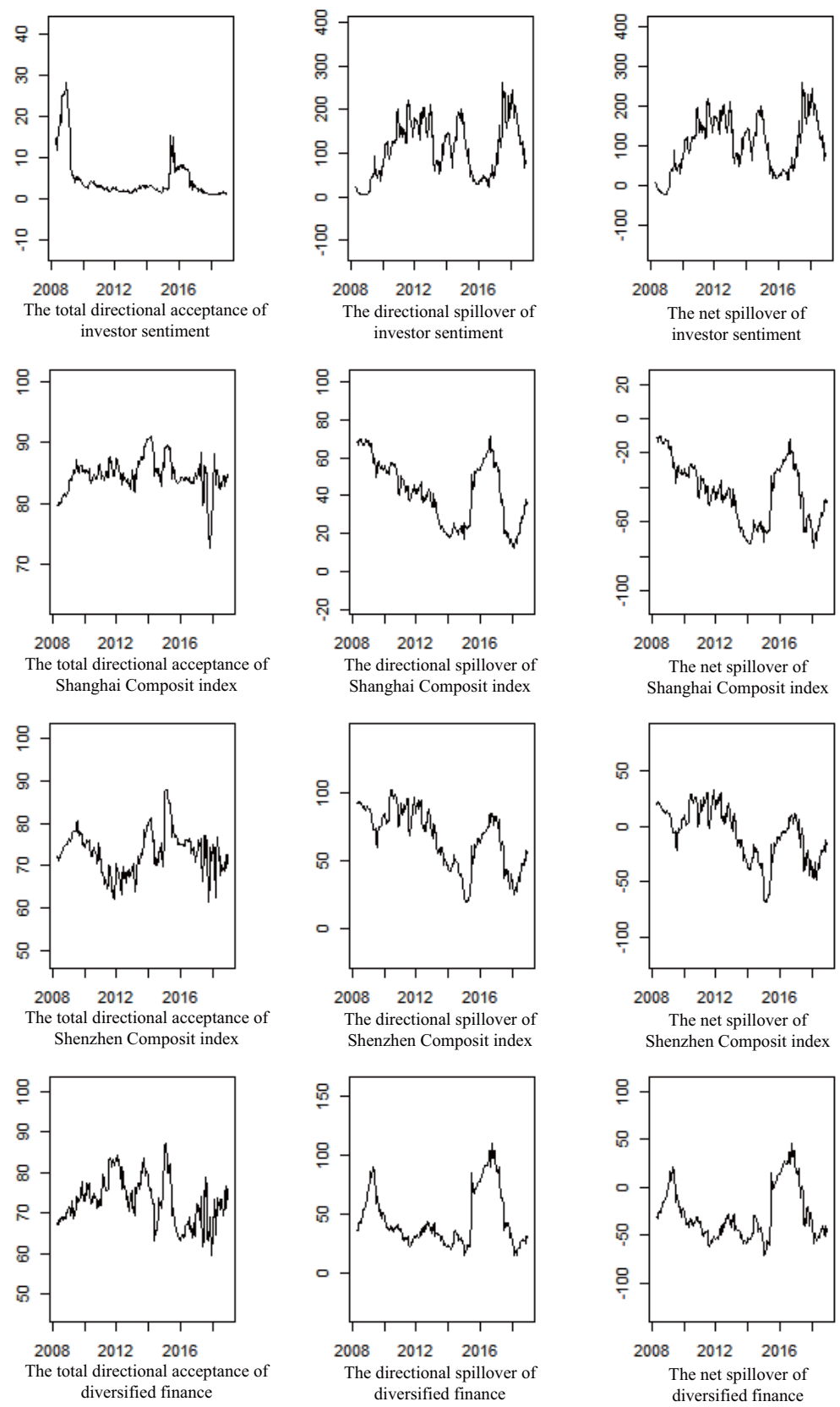

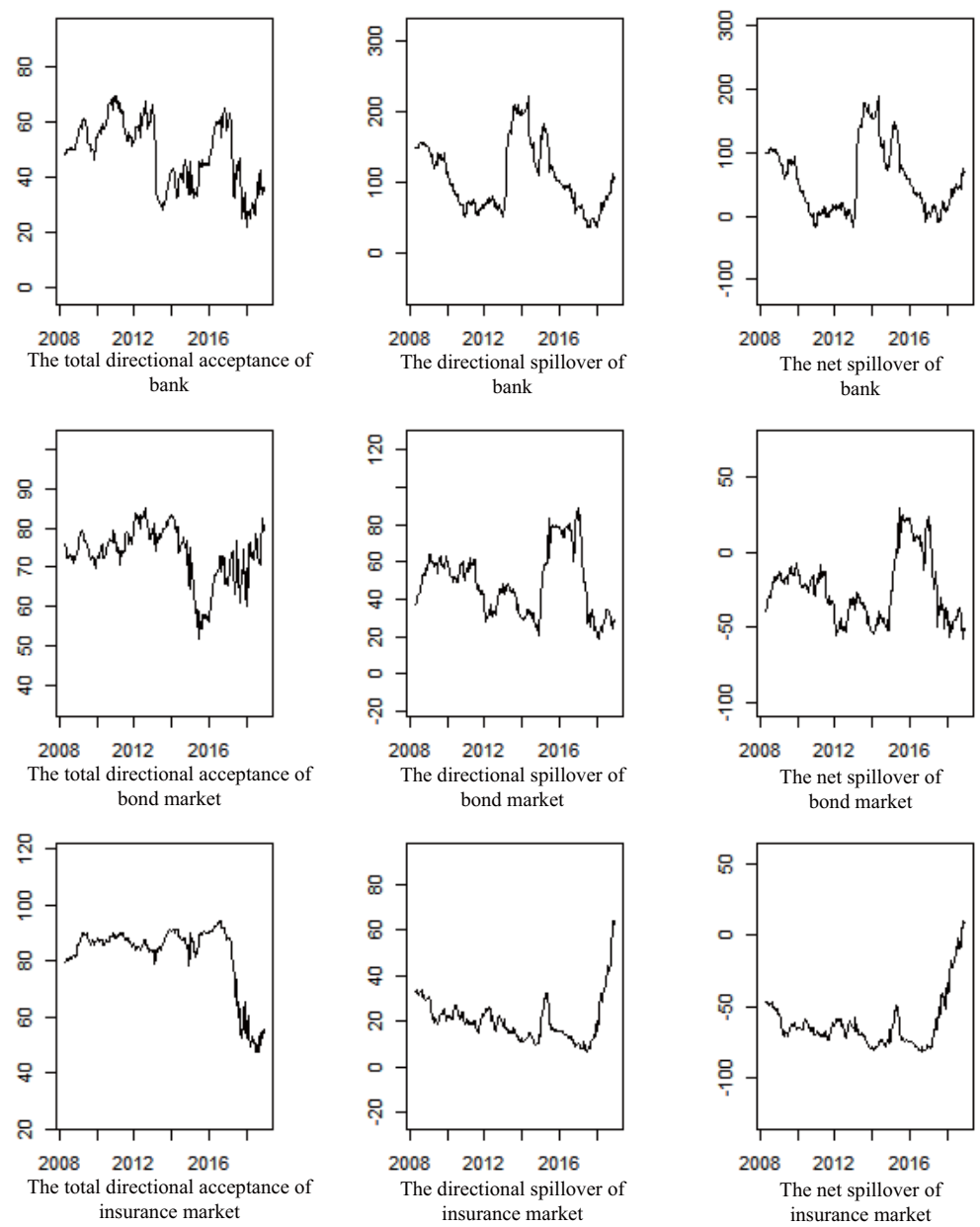

Figure 6 The directional spillover index and net spillover index between the investor sentiment and each market at the short-term scale

4) Robustness test

In order to test the robustness of total spillover effect at the short-term scale, 200-day and 300-day sliding windows and 10-step and 30-step prediction steps were selected to carry out robustness test. The test results are presented in Figure 7 and Figure 8. Despite the size of the sliding window and the prediction step, the dynamic spillovers at the short-term scale show similar patterns, indicating that the short-term scale analysis results have high robustness and consistency.

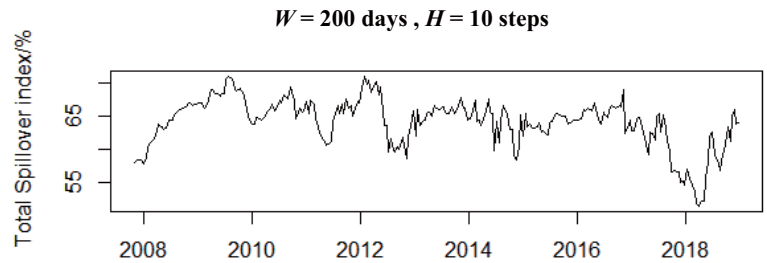

Figure 7 The dynamic spillover index of 200-day sliding windows and 10-step prediction steps at the short-term scale 


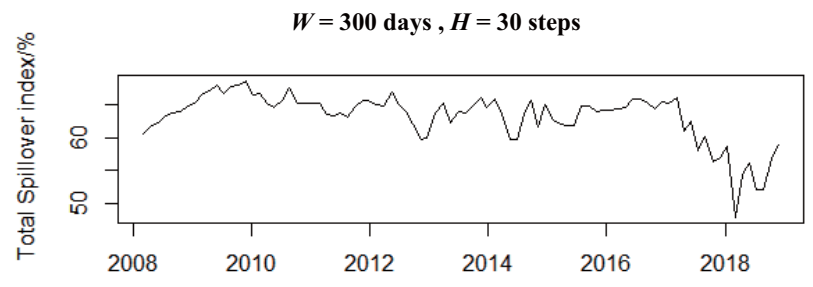

Figure 8 The dynamic spillover index of 300-day sliding windows and 30-step prediction steps at the short-term scale

\subsubsection{Analysis of Medium-Term and Long-Term Scale Spillover Effect}

In order to deeply study the fluctuation relationship between investor sentiment and market indexes at medium-term and long-term scales, the correlation degree as well as leading and lagging relationship between variables were tested according to the time difference correlation coefficient between variables. Variables M1, M2, M3, M4, M5, M6, M7 and variables L1, L2, L3, L4, L5, L6, L7 respectively represent medium-term and long-term investor sentiment, Shanghai Composite Index, Shenzhen Component Index, SWS Diversified Financial Index, SWS Bank Index, SWS Bond Index and SWS Insurance Index.

It can be seen from Figure 9 that the investor sentiment has a strong correlation with SWS Bond, SWS Diversified Finance and Shanghai Composite Index at the medium-term scale. At the long-term scale, investor sentiment is strongly correlated with SWS Bond, SWS Bank, Shanghai Composite Index and Shenzhen Component Index, compared with the medium term. In the medium term, the correlation of SWS Bond, SWS Diversified Finance and Shanghai Composite Index with investor sentiment $(-\mathrm{i})$ is stronger than that in the same period, while the correlation with investor sentiment $(+\mathrm{i})$ is weaker than that in the same period, indicating that the medium-term fluctuation of investor sentiment precedes that of other variables. Investor sentiment $(-\mathrm{i})$ and $(+\mathrm{i})$ has weaker correlation with SWS Bond, SWS Bank, Shanghai Composite Index and Shenzhen Component Index in the long run than that in the same period, indicating investor sentiment has no obvious leading and lagging relationship with other variables.

\begin{tabular}{|c|c|c|c|c|c|c|c|c|c|}
\hline \multicolumn{5}{|c|}{$\begin{array}{l}\text { Date: } 06 / 08 / 19 \text { Time: } 16: 11 \\
\text { Sample: } 1 / 24 / 2007 \text { 3/12/2018 } \\
\text { Included observations: } 2904 \\
\text { Correlations are asymptotically consistent approximations }\end{array}$} & \multicolumn{5}{|c|}{$\begin{array}{l}\text { Date: } 06 / 08 / 19 \text { Time: } 16: 11 \\
\text { Sample: } 1 / 24 / 20073 / 12 / 2018 \\
\text { Included observations: } 2904 \\
\text { Correlations are asymptotically consistent approximations }\end{array}$} \\
\hline M7,M1(-i) & $M 7, M 1(+i)$ & i & lag & lead & M6,M1(-i) & $M 6, M 1(+i)$ & $\mathrm{i}$ & lag & lead \\
\hline ص & 口 & 0 & 0.3232 & 0.3232 & מי & י & 0 & 0.6410 & 0.6410 \\
\hline ש & ש & 1 & 0.3260 & 0.3166 & מש & 正 & 1 & 0.6431 & 0.6357 \\
\hline ש曰 & ص & 2 & 0.3259 & 0.3094 & מיבי & ए & 2 & 0.6433 & 0.6290 \\
\hline 口 & 曰 & 3 & 0.3261 & 0.3037 & י & 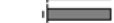 & 3 & 0.6439 & 0.6237 \\
\hline ש & 曰 & 4 & 0.3262 & 0.3006 & מיבי & 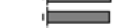 & 4 & 0.6440 & 0.6203 \\
\hline ש & 曰 & 5 & 0.3260 & 0.2977 & 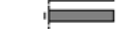 & 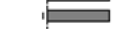 & 5 & 0.6432 & 0.6164 \\
\hline ש & ש & 6 & 0.3270 & 0.2932 & 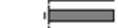 & 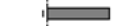 & 6 & 0.6428 & 0.6115 \\
\hline ש曰" & 曰 & 7 & 0.3286 & 0.2899 & 正 & ב & 7 & 0.6423 & 0.6074 \\
\hline ש & 曰 & 8 & 0.3313 & 0.2889 & ב & 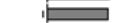 & 8 & 0.6420 & 0.6041 \\
\hline ש & 曰 & 9 & 0.3343 & 0.2803 & 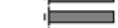 & 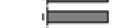 & 9 & 0.6419 & 0.5907 \\
\hline 巴Е & 曰 & 10 & 0.3366 & 0.2613 & 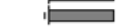 & 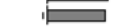 & 10 & 0.6419 & 0.5664 \\
\hline
\end{tabular}




\begin{tabular}{|c|c|c|c|c|c|c|c|c|c|}
\hline \multicolumn{5}{|c|}{$\begin{array}{l}\text { Date: } 06 / 08 / 19 \text { Time: } 16: 12 \\
\text { Sample: } 1 / 24 / 20073 / 12 / 2018 \\
\text { Included observations: } 2904 \\
\text { Correlations are asymptotically consistent approximations }\end{array}$} & \multicolumn{5}{|c|}{$\begin{array}{l}\text { Date: 06/08/19 Time: } 16: 12 \\
\text { Sample: } 1 / 24 / 20073 / 12 / 2018 \\
\text { Included observations: } 2904 \\
\text { Correlations are asymptotically consistent approximations }\end{array}$} \\
\hline M5,M1(-i) & M5,M1(+i) & $i$ & lag & lead & M4,M1(-i) & $M 4, M 1(+i)$ & i & lag & lead \\
\hline $\begin{array}{l}\text { 当 } \\
\text { 当 } \\
\text { 当 } \\
\text { 当 } \\
\text { 当 } \\
\end{array}$ & 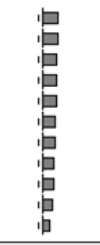 & \begin{tabular}{|r}
0 \\
1 \\
2 \\
3 \\
4 \\
5 \\
6 \\
7 \\
7 \\
8 \\
9 \\
10 \\
\end{tabular} & $\begin{array}{l}0.1624 \\
0.1682 \\
0.1701 \\
0.1722 \\
0.1732 \\
0.1728 \\
0.1736 \\
0.1754 \\
0.1783 \\
0.1810 \\
0.1833 \\
\end{array}$ & $\begin{array}{l}0.1624 \\
0.1537 \\
0.1449 \\
0.1380 \\
0.1337 \\
0.1292 \\
0.1231 \\
0.1185 \\
0.1167 \\
0.1045 \\
0.0786 \\
\end{array}$ & שנ" & 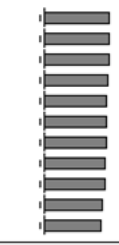 & \begin{tabular}{|r}
0 \\
1 \\
2 \\
3 \\
4 \\
5 \\
6 \\
7 \\
8 \\
9 \\
9 \\
10 \\
\end{tabular} & $\begin{array}{l}0.6471 \\
0.6506 \\
0.6521 \\
0.6540 \\
0.6559 \\
0.6569 \\
0.6579 \\
0.6590 \\
0.6603 \\
0.6617 \\
0.6630 \\
\end{array}$ & $\begin{array}{l}0.6471 \\
0.6411 \\
0.6338 \\
0.6272 \\
0.6215 \\
0.6160 \\
0.6098 \\
0.6040 \\
0.5975 \\
0.5803 \\
0.5543 \\
\end{array}$ \\
\hline \multicolumn{5}{|c|}{$\begin{array}{l}\text { Date: } 06 / 08 / 19 \text { Time: } 16: 12 \\
\text { Sample: } 1 / 24 / 20073 / 12 / 2018 \\
\text { Included observations: } 2904 \\
\text { Correlations are asymptotically consistent approximations }\end{array}$} & \multicolumn{5}{|c|}{$\begin{array}{l}\text { Date: } 06 / 08 / 19 \text { Time: } 16: 13 \\
\text { Sample: } 1 / 24 / 20073 / 12 / 2018 \\
\text { Included observations: } 2904 \\
\text { Correlations are asymptotically consistent approximations }\end{array}$} \\
\hline M3,M1(-i) & M3,M1(+i) & $\mathrm{i}$ & lag & lead & M2,M1(-i) & $M 2, M 1(+i)$ & $\mathrm{i}$ & lag & lead \\
\hline 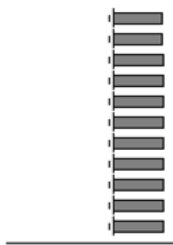 & 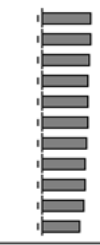 & $\mid \begin{array}{r}0 \\
1 \\
2 \\
3 \\
4 \\
5 \\
6 \\
7 \\
8 \\
9 \\
10\end{array}$ & $\begin{array}{l}0.4780 \\
0.4821 \\
0.4844 \\
0.4870 \\
0.4894 \\
0.4910 \\
0.4930 \\
0.4945 \\
0.4957 \\
0.4971 \\
0.4983 \\
\end{array}$ & $\begin{array}{l}0.4780 \\
0.4711 \\
0.4624 \\
0.4549 \\
0.4491 \\
0.4429 \\
0.4354 \\
0.4289 \\
0.4229 \\
0.4028 \\
0.3695 \\
\end{array}$ & 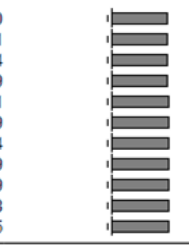 & 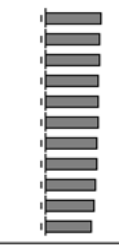 & \begin{tabular}{|r}
0 \\
1 \\
2 \\
3 \\
4 \\
4 \\
5 \\
6 \\
7 \\
8 \\
9 \\
10 \\
\end{tabular} & $\begin{array}{l}0.5414 \\
0.5451 \\
0.5467 \\
0.5486 \\
0.5502 \\
0.5507 \\
0.5518 \\
0.5530 \\
0.5542 \\
0.5554 \\
0.5566 \\
\end{array}$ & $\begin{array}{l}0.5414 \\
0.5351 \\
0.5279 \\
0.5219 \\
0.5175 \\
0.5124 \\
0.5060 \\
0.5006 \\
0.4961 \\
0.4807 \\
0.4549 \\
\end{array}$ \\
\hline \multicolumn{5}{|c|}{$\begin{array}{l}\text { Date: 06/08/19 Time: } 16: 13 \\
\text { Sample: } 1 / 24 / 20073 / 12 / 2018 \\
\text { Included observations: } 2904 \\
\text { Correlations are asymptotically consistent approximations }\end{array}$} & \multicolumn{5}{|c|}{$\begin{array}{l}\text { Date: } 06 / 08 / 19 \text { Time: } 16: 14 \\
\text { Sample: } 1 / 24 / 20073 / 12 / 2018 \\
\text { Included observations: } 2904 \\
\text { Correlations are asymptotically consistent approximations }\end{array}$} \\
\hline L7,L1(-i) & $L 7, L 1(+i)$ & $\mathrm{i}$ & lag & lead & L6,L1(-i) & $\mathrm{L} 6, \mathrm{~L} 1(+\mathrm{i})$ & $\mathrm{i}$ & lag & lead \\
\hline 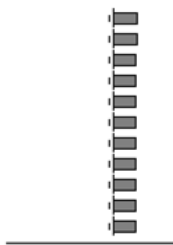 & 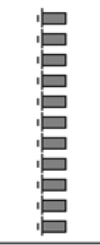 & \begin{tabular}{|r}
0 \\
1 \\
2 \\
3 \\
4 \\
5 \\
5 \\
6 \\
7 \\
8 \\
9 \\
10 \\
\end{tabular} & $\begin{array}{l}0.2323 \\
0.2305 \\
0.2287 \\
0.2268 \\
0.2250 \\
0.2232 \\
0.2213 \\
0.2195 \\
0.2177 \\
0.2159 \\
0.2140 \\
\end{array}$ & $\begin{array}{l}0.2323 \\
0.2331 \\
0.2339 \\
0.2346 \\
0.2354 \\
0.2361 \\
0.2368 \\
0.2376 \\
0.2383 \\
0.2391 \\
0.2398 \\
\end{array}$ & $\begin{array}{l}3 \\
1 \\
9 \\
6 \\
4 \\
1 \\
3 \\
6 \\
3 \\
1 \\
1 \\
3\end{array}$ & 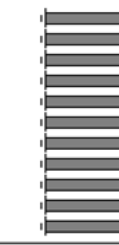 & \begin{tabular}{|r}
0 \\
1 \\
2 \\
3 \\
4 \\
5 \\
6 \\
7 \\
8 \\
8 \\
9 \\
10 \\
\end{tabular} & $\begin{array}{l}0.9974 \\
0.9961 \\
0.9949 \\
0.9936 \\
0.9923 \\
0.9910 \\
0.9897 \\
0.9884 \\
0.9871 \\
0.9859 \\
0.9846 \\
\end{array}$ & $\begin{array}{l}0.9974 \\
0.9963 \\
0.9952 \\
0.9941 \\
0.9930 \\
0.9919 \\
0.9909 \\
0.9898 \\
0.9887 \\
0.9876 \\
0.9865 \\
\end{array}$ \\
\hline \multicolumn{5}{|c|}{$\begin{array}{l}\text { Date: } 06 / 08 / 19 \text { Time: } 16: 14 \\
\text { Sample: } 1 / 24 / 20073 / 12 / 2018 \\
\text { Included observations: } 2904 \\
\text { Correlations are asymptotically consistent approximations }\end{array}$} & \multicolumn{5}{|c|}{$\begin{array}{l}\text { Date: 06/08/19 Time: } 16: 15 \\
\text { Sample: } 1 / 24 / 2007 \text { 3/12/2018 } \\
\text { Included observations: } 2904 \\
\text { Correlations are asymptotically consistent approximations }\end{array}$} \\
\hline \multirow[t]{2}{*}{ L5,L1(-i) } & L5,L1(+i) & $\mathrm{i}$ & lag & lead & L4,L1(-i) & $L 4, L 1(+i)$ & $i$ & lag & lead \\
\hline & " & \begin{tabular}{|r|}
0 \\
1 \\
2 \\
3 \\
4 \\
5 \\
6 \\
7 \\
8 \\
9 \\
10 \\
\end{tabular} & $\begin{array}{l}0.8536 \\
0.8518 \\
0.8499 \\
0.8481 \\
0.8463 \\
0.8444 \\
0.8426 \\
0.8408 \\
0.8389 \\
0.8371 \\
0.8353\end{array}$ & $\begin{array}{l}0.8536 \\
0.8532 \\
0.8527 \\
0.8523 \\
0.8518 \\
0.8514 \\
0.8509 \\
0.8504 \\
0.8500 \\
0.8495 \\
0.8491 \\
\end{array}$ & 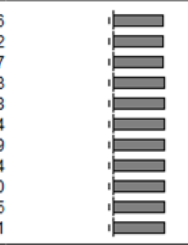 & 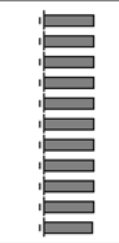 & \begin{tabular}{|r}
0 \\
1 \\
2 \\
3 \\
4 \\
5 \\
6 \\
7 \\
8 \\
9 \\
10
\end{tabular} & $\begin{array}{l}0.4983 \\
0.4991 \\
0.4999 \\
0.5007 \\
0.5015 \\
0.5023 \\
0.5031 \\
0.5039 \\
0.5047 \\
0.5055 \\
0.5063\end{array}$ & $\begin{array}{l}0.4983 \\
0.4968 \\
0.4953 \\
0.4938 \\
0.4923 \\
0.4908 \\
0.4893 \\
0.4878 \\
0.4863 \\
0.4848 \\
0.4834\end{array}$ \\
\hline \multicolumn{5}{|c|}{$\begin{array}{l}\text { Date: 06/08/19 Time: } 16: 16 \\
\text { Sample: } 1 / 24 / 20073 / 12 / 2018 \\
\text { Included observations: } 2904 \\
\text { Correlations are asymptotically consistent approximations } \\
\end{array}$} & \multicolumn{5}{|c|}{$\begin{array}{l}\text { Date: 06/08/19 Time: } 16: 16 \\
\text { Sample: } 1 / 24 / 2007 \text { 3/12/2018 } \\
\text { Included observations: } 2904 \\
\text { Correlations are asymptotically consistent approximations }\end{array}$} \\
\hline L3,L1(-i) & $\mathrm{L} 3, \mathrm{~L} 1(+\mathrm{i})$ & $\mathrm{i}$ & lag & lead & $\mathrm{L} 2, \mathrm{~L} 1(-\mathrm{i})$ & $\mathrm{L} 2, \mathrm{~L} 1(+\mathrm{i})$ & $i$ & lag & lead \\
\hline 口 & 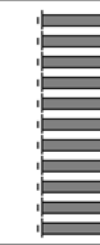 & $\begin{array}{r}0 \\
1 \\
2 \\
3 \\
4 \\
5 \\
6 \\
7 \\
8 \\
9 \\
10 \\
\end{array}$ & $\begin{array}{l}0.8892 \\
0.8889 \\
0.8885 \\
0.8882 \\
0.8879 \\
0.8876 \\
0.8873 \\
0.8870 \\
0.8867 \\
0.8864 \\
0.8861\end{array}$ & $\begin{array}{l}0.8892 \\
0.8876 \\
0.8861 \\
0.8846 \\
0.8831 \\
0.8815 \\
0.8800 \\
0.8785 \\
0.8770 \\
0.8754 \\
0.8739\end{array}$ & $\begin{array}{l}2 \\
5 \\
1 \\
5 \\
1 \\
5 \\
0 \\
5 \\
0 \\
4 \\
9\end{array}$ & 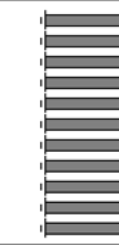 & \begin{tabular}{|r}
0 \\
1 \\
2 \\
3 \\
4 \\
5 \\
6 \\
7 \\
8 \\
9 \\
10
\end{tabular} & $\begin{array}{l}0.9912 \\
0.9898 \\
0.9884 \\
0.9870 \\
0.9857 \\
0.9843 \\
0.9829 \\
0.9815 \\
0.9802 \\
0.9788 \\
0.9774\end{array}$ & $\begin{array}{l}0.9912 \\
0.9902 \\
0.9891 \\
0.9881 \\
0.9871 \\
0.9861 \\
0.9850 \\
0.9840 \\
0.9830 \\
0.9820 \\
0.9809\end{array}$ \\
\hline
\end{tabular}

Figure 9 The time difference correlation coefficient between variables at long-term scales 


\section{Conclusion}

This study investigated the correlation between investor sentiment and Shanghai Composite Index, Shenzhen Component Index, SWS Diversified Finance, SWS Bank, SWS Bond as well as SWS Insurance according to the spillover index. In order to study the correlation among the variables at different scales, BEMD method was employed to decompose and integrate the variables, and the static and dynamic correlations between investor sentiment and the variables were analyzed at multiple scales. The study results demonstrate that the total internal spillover index between investor sentiment and Shanghai Composite Index, Shenzhen Component Index and financial industries represented by SWS Index is up to $65.52 \%$, and there is a strong correlation among the variables. Investor sentiment is an important influencing factor of the securities market. The dynamic spillover index shows strong correlation between investor sentiment and markets. At a short-term scale, compared with the original scale data, except that the internal spillover of investor sentiment and the banking industry increases, other indexes decrease in different degrees. Apart from investor sentiment and the bank industry, the total directional acceptance of each market at the short-term scale is larger than that at the original scale. Compared with the original scale data, except that the internal spillover of investor sentiment and banking industry increases, other indexes decrease in different degrees. The dynamic spillover curve is relatively flat in the short term, and the spillover effect is small. In the medium term, investor sentiment has a strong correlation with SWS Bond, SWS Diversified Finance and Shanghai Composite Index. In the long term, investor sentiment is strongly correlated with SWS Bond, SWS Bank, Shanghai Composite Index and Shenzhen Component Index than that in the medium term.

Research prospects: The research in this paper is based on the consistency of data. But the data in reality will inevitably be affected by external events, and the compilation method of available data may also change, such as the official opening of the science and technology innovation board on June 13, 2019 and the new compilation method of the Shanghai Composite Index on July 22, 2020. In the future, on the one hand, we can try to improve the compilation method of investor sentiment index to eliminate the impact of external events on the data, on the other hand, we can try to improve the analysis method to eliminate the impact of external events on the data.

\section{References}

[1] De Long J B, Shleifer A, Summers L H, et al. Noise trader risk in financial markets. Journal of political Economy, 1990, 98(4): 703-738.

[2] Stein J C. Rational capital budgeting in an irrational world. The Journal of Business, 1996, 69(4): 429-455.

[3] Sayim M, Rahman H. An examination of U.S. institutional and individual investor sentiment effect on the Turkish stock market. Global Finance Journal, 2015, 26: 1-17.

[4] Kadilli A. Predictability of stock returns of financial companies and the role of investor sentiment: A multi-country analysis. Journal of Financial Stability, 2015, 21: 26-45.

[5] Chen M P, Chen P F, Lee C C. Asymmetric effects of investor sentiment on industry stock returns: Panel data evidence. Emerging Markets Review, 2013, 14: 35-54.

[6] Chung S L, Hung C H, Yeh C Y. When does investor sentiment predict stock returns?. Journal of Empirical Finance, 2012, 19(2): 217-240. 
[7] Ni Z X, Wang D Z, Xue W J. Investor sentiment and its nonlinear effect on stock returns — New evidence from the Chinese stock market based on panel quantile regression model. Economic Modelling, 2015, 50: $266-274$.

[8] Hudson Y, Green C J. Is investor sentiment contagious? International sentiment and UK equity returns. Journal of Behavioral and Experimental Finance, 2015, 5: 46-59.

[9] Zhang Q, Yang S E. Noise trading, investor sentiment volatility and stock returns. Systems Engineering Theory and Practice, 2009, 29(3): 40-47.

[10] Chi L X, Zhuang X T. A study on the relationship between investor sentiment and the stock market returns in China-based on panel data model. Management Review, 2011, 23(6): 41-48.

[11] Dong X W, Zhang X D, Liu W Q. A study of binary relationship between investor sentiment and stock market returns - Study using quantile regression. Economic Management, 2013, 35(6): 103-111.

[12] Li H L, Feng C E. Relationship between investor sentiment and stock indices fluctuation based on EEMD. Systems Engineering — Theory and Practice, 2014, 34(10): 2495-2503.

[13] Peters E E. Fractal market analysis: Applying chaos theory to investment and economics. John Wiley and Sons, 1994.

[14] Xie Q W, Xuan B, Li J P, et al. Analysis and application of empirical mode decomposition algorithm. Systems Engineering — Theory and Practice, 2009, 29(11): 168-176.

[15] Xie Q W, Xuan B, Peng S, et al. Bandwidth empirical mode decomposition and its application. International Journal of Wavelets, Multiresolution and Information Processing, 2008, 6(6): 777-798.

[16] Wang X, Cai J L, Tang L, et al. VaR measurement for stock portfolio based on BEMD-Copula-GARCH model. Systems Engineering - Theory and Practice, 2017, 37(2): 303-310.

[17] Wu D S, Li J P, Tang L, et al. A hybrid analysis model for fluctuation characteristics and influence events of live pig price and an empirical study. Systems Engineering — Theory and Practice, 2011, 31(11): 2033-2042.

[18] Sun X L, Yao X Y, Yang Y Y. Multi-scale feature extraction and identification of country risk dynamics: Cases of OPEC countries. Chinese Journal of Management Science, 2015, 23(4): 1-10.

[19] Diebold F X, Yilmaz K. Measuring financial asset return and volatility spillovers, with application to global equity markets. Economic Journal, 2009, 119(534): 158-171.

[20] Diebold F X, Yilmaz K. Better to give than to receive: Predictive directional measurement of volatility spillovers. International Journal of Forecasting, 2012, 28(1): 57-66.

[21] Zhang X, Lai K K, Wang S Y. A new approach for crude oil price analysis based on empirical mode decomposition. Energy Economics, 2008, 30(3): 905-918.

[22] Wurgler J A, Baker M P. Investor sentiment and the cross-section of stock returns. The Journal of Finance, 2006, 61(4): 1645-1680. 